\title{
Primary angle-closure glaucoma
}

\section{A review 5 years after bilateral surgery}

\author{
RONALD F. LOWE
}

From the Glaucoma Unit, the Royal Victorian Eye and Ear Hospital, and the Ophthalmic Research Institute of Australia

It is now 20 years since Chandler (1952) advocated peripheral iridectomy for the prophylaxis of primary angle-closure glaucoma in the apparently uninvolved eye. Following later enthusiastic reports (Bain, I957; Lowe, I962) this recommendation was accepted by perhaps the majority of ophthalmologists, but in travelling around the world I have found it firmly rejected by others. Opposition rests mainly on suggested surgical risks to a "normal" eye, and in late complications such as lens opacities.

The surgical risks have been shown to be definite but small (Lowe, I962; Douglas and Strachan, 1967; Ghoshal and Blaxter, 1969; Luke, I969), but in the long term they are less than those following medical treatment (Bain, I957; Lowe, 1962; Douglas and Strachan, 1967). More recently, Sugar (1970) reported considerable late refractive changes, whereas Kirsch (1970) in a preliminary report and a recent personal communication (1972) stated that the fear of cataract is unwarranted.

In view of these uncertainties, I planned a review of well-documented cases ro years after bilateral surgery. So many patients had died or could not be traced, however, that the period was reduced to 5 years.

\section{Subjects}

During 197 I and 1972, I sought for review all patients who had presented with acute or intermittent angle-closure glaucoma to the Royal Victorian Eye and Ear Hospital 5 years previously. All had been examined by me and detailed records had been compiled shortly after the original diagnosis. All were considered to have uncomplicated primary angle-closure glaucoma with a normally functioning fellow eye. Four cases with virtual bilateral onset and three with known chronic simple glaucoma (mixed glaucoma) were not included in the review.

The final list totalled $5^{2}$ patients with an age range of 39 to 86 years at the time of surgery 5 years ago; 26 (50 per cent.) attended when requested - twenty females and six males. These proportions approximate to the sex distribution of larger series here (Lowe, 1961). All were of European stock.

\section{Losses}

Of the $5^{2}$ patients, eight had died ( 15 per cent.) and ten ( 19 per cent.) were considered to have probably died at the time of review. The ages of the latter would have been $71,72,73,80,81,8_{3}$, $83,87,88,9 \mathrm{I}$ years; they had attended the hospital at regular intervals and were known to be in failing health, and at sometime during the 5 years they had failed to report for their out-patient appointments and letters sent to them were returned by the Post Office.

Eight patients stopped attending when discharged from hospital after surgery and they could not be traced. Their ages at the time of review would have been $44,53,58,62,71,73,78,81$ years. Two of the younger patients had only intermittent attacks almost certainly cured by surgery, others 
were probably symptom-free and saw no benefit from repeated attendance, and the elderly may have died.

Thus, one-third (and perhaps 40 per cent.) of the patients who presented with primary acute-angle closure glaucoma had died within 5 years of the attack.

\section{Types of angle-closure glaucoma}

Of the 26 patients who attended for review, 23 came originally during an attack of primary acute angle-closure glaucoma ( 12 had no previous warning, 9 had previous intermittent attacks, two had acute on-creeping (chronic) angle closure). One patient had only intermittent attacks of angle closure in one eye, and two had quiet creeping angle-closure glaucoma in one eye with severe visual loss, but no acute attacks.

\section{Surgery}

Both eyes of all patients were submitted to surgery. For the eyes presenting with angle-closure glaucoma, those with closed angles that opened with medical treatment had iridectomy ( 5 peripheral iridectomies, 2 full width). When angles remained closed despite intensive medical treatment, a drainage operation was performed (iridencleisis 6; Scheie's sclerocautery 3). Eyes needing a drainage operation were usually damaged by acute glaucoma before surgery. All fellow eyes had a sealed peripheral iridectomy.

\section{Visual acuity}

Table I shows that after 5 years the eyes that had prophylactic surgery were generally faring well. 73 per cent. of these eyes had $6 / 9$ or better vision and 16 per cent. had 6/1 2 or $6 / 18$ vision, so that 89 per cent. had $6 / 18$ or better vision. One patient with $6 / 12$ vision was aged 82 years and the two with $6 / 18$ vision were aged 75 and 80 years and had macular holes. Three patients had $6 / 24$ to $6 / 60$ vision - one aged 63 years with $6 / 24$ vision and one aged 77 years with $6 / 36$ vision had macular degeneration; one aged 81 years had 6/6o vision with lens opacities too dense to permit a view of the fundus. No one had less than 6/6o vision.

The above visual results are gratifying and accord well with the visual acuity expected for people of similar ages.

Even most of the eyes involved with angle-closure glaucoma fared well considering their state at the time treatment was commenced. 42 per cent. had vision of $6 / 9$ or better while 54 per cent. had vision of $6 / 18$ or better, but 24 per cent. were virtually blind. Eyes with advanced creeping (chronic) angle-closure glaucoma had poor vision when first examined and vision deteriorated despite drainage operations.

Eyes which required drainage had the most severe damage from the glaucoma and late vision was very poor compared with the eyes in which only peripheral iridectomy could be performed. Even these eyes with curvative peripheral iridectomy had less clear vision than the eyes with prophylactic peripheral iridectomies, thus showing the effect of angleclosure glaucoma in reducing vision despite opening of the angle with medical treatment.

\section{Changes in refraction}

Table II shows changes in refraction 5 years after surgery. After prophylactic peripheral iridectomy, nearly 40 per cent. of eyes had no change in refraction; but in a little over 50 per cent. of eyes in this group refraction changed in the direction of myopia. Angleclosure glaucoma predominantly involves hypermetropic eyes, so that of the fourteen that became more myopic nine remained hypermetropic.

Amongst the nineteen eyes that had been involved with angle-closure glaucoma and that could be tested, nine became more myopic, but only four remained hypermetropic. 
Table I Visual acuity of 26 patients 5 years after bilateral surgery for angle-closure glaucoma

\begin{tabular}{|c|c|c|c|c|}
\hline \multirow{2}{*}{ Visual acuity } & \multicolumn{3}{|c|}{ Affected eyes } & \multirow{2}{*}{$\frac{\text { Fellow eyes }}{\text { Peripheral iridectomy }}$} \\
\hline & $\overline{\text { Drainage }}$ & Iridectomy & Totals & \\
\hline $\begin{array}{l}6 / 5 \\
6 / 6\end{array}$ & - & 3 & & $\begin{array}{l}6 \\
6\end{array}$ \\
\hline $6 / 9$ & - & $\begin{array}{l}3 \\
2\end{array}$ & & 7 \\
\hline Subtotal $6 / 5-6 / 9$ & I & Io & II $\left(4^{2}\right.$ per cent. $)$ & 19 (73 per cent.) \\
\hline $\begin{array}{l}6 / 12 \\
6 / 18\end{array}$ & $\overline{-}$ & $\begin{array}{l}1 \\
2\end{array}$ & & $\begin{array}{l}2 \\
2\end{array}$ \\
\hline Subtotal $6 / 5-6 / 18$ & $\mathbf{I}$ & 13 & 14 (54 per cent.) & 23 (89 per cent.) \\
\hline $6 / 24$ & I & - & & I \\
\hline $6 / 36$ & 2 & 2 & & I \\
\hline $6 / 60$ & - & - & & I \\
\hline$\overline{\text { Subtotal } 6 / 24-6 / 60}$ & 3 & 2 & 5 (19 per cent.) & 3 (I I per cent.) \\
\hline \multirow{3}{*}{$\begin{array}{l}\text { 3/6o } \\
\text { Hand movements } \\
\text { No perception } \\
\text { of light }\end{array}$} & & - & & - \\
\hline & 2 & 2 & & - \\
\hline & 3 & - & & - \\
\hline Subtotal blind & 5 & 2 & 7 (27 per cent.) & - \\
\hline Totals & 9 & 17 & 26 & 26 \\
\hline
\end{tabular}

Table II Spherical equivalent of change in refraction for 26 patients 5 years after bilateral surgery for angle-closure glaucoma

\begin{tabular}{|c|c|c|c|c|}
\hline \multirow{2}{*}{$\begin{array}{l}\text { Change in } \\
\text { refraction } \\
\text { (dioptres) }\end{array}$} & \multicolumn{3}{|c|}{ Affected eyes } & \multirow{2}{*}{$\begin{array}{l}\text { Fellow eyes } \\
\text { Peripheral iridectomy }\end{array}$} \\
\hline & Drainage & Iridectomy & Total & \\
\hline Nil & - & $\begin{array}{l}6(23 \\
\text { per cent. })\end{array}$ & 6 & Io (38 per cent.) \\
\hline+0.75 to $+2 \cdot 0$ & I & 2 & 3 & 2 (8 per cent.) \\
\hline $\begin{array}{l}-0.75 \text { to }-1 \cdot 25 \\
-1.5 \text { to }-3.0 \\
-3.25 \text { to }-5.0 \\
-5.0 \text { to }-7.0\end{array}$ & $\frac{\mathbf{I}}{\mathbf{I}}$ & $\begin{array}{l}\mathbf{1} \\
3 \\
\mathbf{1} \\
2\end{array}$ & & $\begin{array}{l}5 \\
5 \\
2 \\
2\end{array}$ \\
\hline Total myopes & 2 & 7 & 9 & I4 (54 per cent.) \\
\hline $\begin{array}{l}\text { Could not } \\
\text { determine }\end{array}$ & 6 & 2 & 8 & $\overline{-}$ \\
\hline Totals & 9 & 17 & 26 & 26 \\
\hline
\end{tabular}

The myopic refractive change in itself caused little trouble to the patients, but as the myopia was caused by lens sclerosis the lenses associated with the higher degrees of myopia were not as clear as in the eyes in which refraction had not changed. 
Lenses

The state of the lenses is shown in Table III. These are descriptions from slit-lamp appearances and the divisions are somewhat arbitrary, especially the divisions into degrees of lens sclerosis.

Table III State of lenses in 26 patients 5 years after bilateral surgery for angle-closure glaucoma

\begin{tabular}{|c|c|c|c|c|}
\hline \multirow{2}{*}{ State of lenses } & \multicolumn{3}{|c|}{ Affected eyes } & \multirow{2}{*}{$\frac{\text { Fellow eyes }}{\text { Peripheral iridectomy }}$} \\
\hline & Drainage & Iridectomy & Totals & \\
\hline Clear & 2 & 10 & 12 & I 6 \\
\hline Sclerosis $\mathrm{I} *$ & 2 & 2 & 4 & 3 \\
\hline Sclerosis $2 *$ & I & 1 & 2 & 2 \\
\hline Sclerosis $3^{*}$ & 3 & 2 & 5 & $2 \dagger$ \\
\hline Cortical cataracts & - & 1 & I & 3 \\
\hline Lens in vitreous & I & I & 2 & - \\
\hline Totals & 9 & 17 & 26 & 26 \\
\hline
\end{tabular}

* arbitrary degrees of lens sclerosis

$\dagger$ one thick cataract nearing surgery

Of the eyes that had prophylactic peripheral iridectomy, 6o per cent. had "clear" lenses, whereas in affected eyes that had curative peripheral iridectomy $4^{6}$ per cent. had "clear" lenses. The difference between the two series reflects the difference in visual acuity noted above.

One eye in the prophylactic series had a thickening cataract that was approaching surgery. The patient was aged $8 \mathrm{I}$ years. In no other eye was cataract extraction imminent, but some of the badly damaged eyes had opaque lenses the extraction of which could not be recommended.

After prophylactic peripheral iridectomy there were no axial lens opacities from posterior synechiae or the surgical technique.

\section{Posterior synechiae}

The presence and effect of posterior synechiae upon the lenses of eyes that had prophylactic peripheral iridectomy were assessed after pupil dilatation with io per cent. phenylephrine eye drops. Synechiae were grouped according to the percentage of pupil circumference adherent to the lens. Table IV shows the results.

Eighteen eyes had freely mobile pupils. The following numbers of eyes had posterior synechiae: three under ro per cent., two approximately 25 per cent., one approximately N 50 per cent., two approximately 75 per cent.

After peripheral iridectomy, pupil mobility was pursued by the use of ro per cent. స્લ phenylephrine eye drops. Despite this, for various reasons, some posterior synechiae $\underset{2}{2}$ formed, but they did so with pupils at least semidilated. The synechiae had no effects upon vision.

\section{Tensions and tonography}

Table V summarizes measurements of ocular tension. These investigations emphasize $\mathbb{D}$ the need for careful postoperative review until the potential for chronic glaucoma can be $\stackrel{\mathbb{\mathbb { D }}}{\varrho}$ fully assessed. 
Table IV Posterior synechiae in 26 eyes 5 years after prophylactic peripheral iridectomy

\begin{tabular}{lrl}
\hline $\begin{array}{l}\text { Percentage of } \\
\text { pupil affected }\end{array}$ & & $\begin{array}{l}\text { Number of } \\
\text { eyes }\end{array}$ \\
\cline { 1 - 1 } Clear & & 18 \\
Under $10 \%$ & & 3 \\
Approx. $25 \%$ & & 2 \\
Approx. $50 \%$ & & 1 \\
Approx. $75 \%$ & 2 \\
\hline
\end{tabular}

Table $\mathbf{V}$ Intraocular tensions and tonography in 26 patients 5 years after bilateral surgery for angle-closure glaucoma

\begin{tabular}{|c|c|c|c|}
\hline \multirow{2}{*}{$\begin{array}{l}\text { Intraocular } \\
\text { tension }\end{array}$} & \multicolumn{2}{|c|}{ Affected eyes } & \multirow{2}{*}{$\frac{\text { Fellow eyes }}{\text { Peripheral iridectomy }}$} \\
\hline & Drainage & Iridectomy & \\
\hline$P 0 \leqq 2 I$ & 7 & 12 & 23 \\
\hline Po $>21$ & 2 & 5 & 3 \\
\hline $\mathrm{Po} / \mathrm{C} \leqslant 100$ & 8 & IO & 20 \\
\hline $\mathrm{Po} / \mathrm{C}>100$ & $\mathbf{I}$ & 6 & 5 \\
\hline Po/C not taken & - & $I^{*}$ & $I^{*}$ \\
\hline
\end{tabular}

* Patient age 86, too dyspnoeic: affected eye had lens luxated into vitreous and $\mathrm{Po}=3 \mathrm{I}$; fellow eye $\mathrm{Po}=12$

In eyes that had been affected by angle-closure glaucoma, residual chronic glaucoma was more likely than in the fellow eyes despite the attempts to minimize this by the preoperative selection between iridectomy and drainage operation.

Of 26 fellow eyes that had prophylactic peripheral iridectomy, 23 showed no postoperative glaucoma, but three patients were considered to have mild chronic simple glaucoma (with open angles) that needed medical treatment. Another two were being watched because ocular tensions were 24 and $23 \mathrm{~mm}$. $\mathrm{Hg}$, but the $\mathrm{G}$ values were $0 \cdot 33$ and $0 \cdot 3 \mathrm{I}$ and the optic discs were normal in appearance.

\section{Visual fields}

When possible, visual fields were charted with either the I/4 or II/4 targets on the Goldmann perimeter or the 2/2000 white target using the Bjerrum screen (Table VI).

Table VI State of visual fields in 26 patients 5 years after bilateral surgery for angle-closure glaucoma

\begin{tabular}{|c|c|c|c|}
\hline $\begin{array}{l}\text { State of } \\
\text { fields }\end{array}$ & $\begin{array}{l}\text { Type of } \\
\text { field test }\end{array}$ & $\begin{array}{l}\text { Affected } \\
\text { eyes }\end{array}$ & $\begin{array}{l}\text { Fellow } \\
\text { eyes }\end{array}$ \\
\hline Normal & $\begin{array}{l}\text { Goldmann } \\
\mathrm{I} / 4 \text { or II } / 4\end{array}$ & II & 16 \\
\hline Normal & $\begin{array}{l}\text { Bjerum } \\
2 / 2000 \text { white } 20^{\circ}+\end{array}$ & 2 J & $5 \int^{2}$ \\
\hline \multirow[t]{2}{*}{$\overline{\text { Reduced }}$} & $\begin{array}{l}\text { Bjerrum } \\
\text { 2/2000 white } 10^{\circ}\end{array}$ & 1) & ? 1 \\
\hline & $\begin{array}{l}\text { Bjerrum } \\
2 / 2000 \text { white } 5^{\circ}\end{array}$ & 2 & - \\
\hline $\begin{array}{l}\text { Could not } \\
\text { chart }\end{array}$ & & 10 & 4 \\
\hline
\end{tabular}

Fields could not be charted for three patients owing to their age. Seven others had affected eyes too badly damaged for field charting. Undamaged eyes had good visual fields. 
2 I fellow eyes that had prophylactic peripheral iridectomies and no chronic simple glaucoma had normal visual fields.

\section{Discussion}

Visual acuity and lens opacities

In the random review of patients who have had angle-closure glaucoma, one can be persuaded that the results are poor, but the systematic review of a group such as this gives one considerable encouragement in the management of this severe eye disease. However, if all patients could be treated early and resolutely, the overall results would be much better.

Many of the eyes that had been affected by angle-closure glaucoma showed considerable structural damage, but by contrast the eyes that had prophylactic surgery were of good appearance. Even when the glaucomatous eyes were not grossly damaged, the patients were well aware of the difference in function between the two eyes.

Of the eyes that had prophylactic peripheral iridectomy, the only long-term anxiety centred upon lens changes that could have beeen attributed to surgery; 60 per cent. showed a change in refraction, and approximately $5^{\circ}$ per cent. showed a myopic change. After 5 years, in most patients, this myopia was of no account in that it merely reduced the hypermetropia. Nevertheless, the myopic changes could be expected to increase with further time.

The lens changes were influenced by age. The three youngest patients who attended for review were then aged 48, 55, and 55 years and showed no change in distance refraction or in visual acuity from 5 years previously. Shaffer and Rosenthal (1970) found that, in normal people aged between $6 \mathrm{r}$ and 70 years, 4.4 per cent. developed cataract, in those over the age of 70 years 19 per cent. developed cataract, but in those between 75 and 90 years 27 per cent. developed cataract. The prognosis is further complicated by the limited life expectancy of the older patients.

In only one fellow eye of the 26 was cataract so advanced that extraction was imminent. The patient was aged 76 at the time of her acute attack and had reached the age of $8 \mathrm{I}$ when reviewed, had meanwhile developed chronic simple glaucoma and was being treated with 4 per cent. pilocarpine eye drops. Apart from this individual and those with macular degeneration (almost certainly independent), no one had less than 6/1 2 vision in the fellow eye.

There appears to be no doubt that prophylactic peripheral iridectomy has an adverse effect upon some lenses, but when assessed in relation to the prevention of angle-closure glaucoma these effects appear to be justified side-reactions.

\section{Late chronic glaucoma}

Surgery prevents angle-closure glaucoma in fellow eyes, stops its recurrence in eyes where angles have opened preoperatively, and arrests creeping (chronic) angle closure (the rare exceptions to this statement are too complex for discussion).

Chronic simple glaucoma will be found sufficiently often for it to be sought, but no more often than may be expected.

\section{Surgery}

For the bilateral surgery of the 26 cases, nine experienced ophthalmologists and eight ophthalmic house-surgeons performed the operations without using operating microscopes. The results might have been better if only one surgical unit had been involved, but as they were done by numerous surgeons of varying calibre they should, overall, reflect what can be expected from surgeons of reasonable experience. 
The techniques used were those of Chandler (1952) or Barkan (I954). Operative complications were of no significance in this series, but unfortunate results are always possible and occasionally occur. There is considerable room for a better method whereby the iris is not prolapsed for excision to make the essential hole in it, and the anterior chamber is virtually always preserved.

Minor improvements have been made in the 5 years since the surgery of this series. More intensive use of prednisolone eye drops before and after surgery has reduced operative reactions including posterior synechiae; and possibly more attention to preservation of the anterior chamber and delicacy of iris reposition may reduce the lens changes that induce myopia.

\section{Conclusions}

This systematic 5-year review supports the curative and prophylactic role of peripheral iridectomy when one eye has been involved in pupil block angle-closure glaucoma, strengthening the recommendation for bilateral surgery. By contrast, peripheral iridectomy cannot be recommended for the prophylaxis of angle-closure glaucoma in eyes having only shallow anterior chambers and narrow angles but without symptoms or signs of angle-closure glaucoma in either eye.

\section{Summary}

52 consecutive patients who had bilateral surgery for angle-closure glaucoma were reviewed after 5 years. One-third and possibly 40 per cent. had died.

When angles were open preoperatively, peripheral iridectomy prevented future angleclosure. Prophylactic peripheral iridectomy affects some lenses, especially to cause a myopic change in refraction, and rarely to cause lens opacities. When assessed in relation to the risks and results of angle-closure glaucoma in the second eye (Lowe, ig62) the effects upon some lenses appear to be justifiable side-reactions. Peripheral iridectomy is not recommended for eyes with only shallow anterior chambers and narrow angles but without symptoms or signs of angle-closure glaucoma in either eye.

These investigations formed part of Research Projects No. I4 of the Ophthalmic Research Institute of Australia (J. Bruce Hamilton Research Fellowship) and No. I 3 of The Royal Victorian Eye and Ear Hospital conducted in the Glaucoma Unit of the Hospital. I wish to thank my colleagues for permission to examine their patients and for access to their records. Dr. Magda Horvat assisted with the investigations.

\section{References}

BAIN, w. E. s. (1957) Brit. J. Ophthal., 4r, I93

BARKAN, O. (1954) Amer. F. Ophthal., 37, 504

Chander, P. A. (1952) Trans. Amer. Acad. Ophthal. Otolaryng., 56, 593, (Discussion); A.M.A. Arch. Ophthal., 47, 695

Douglas, W. H. G., and Strachan, I. м. (1967) Brit. F. Ophthal,, 5I 459

GHOSHAL, T. K., and BlAXTER, P. L. (1969) Ibid., 53, I IO

KIRSCH, R. E. (1970) Invest. Ophthal., 9, 424

LOWE, R. F. (196r) Trans. ophthal. Soc. Aust., 21, 65

(1962) Brit. J. Ophthal., 46, 641

LUKe, s. K. (1969) Canad. F. Ophthal., 4, 346

SHAFFer, R. N., and rosenthal, s. (1970) Amer. 7. Ophthal., 69, 368

sugar, H. s. (1970) Amer. F. Ophthal., 69, 747

A request is submitted that ophthalmologists should publish the results of managing fellow eyes in angle-closure glaucoma without peripheral iridectomy. 